\title{
Sentence-demonstration ability in reading-disabled vs. normal college students
}

\author{
DANIEL W. KEE, PATRICIA E. WORDEN, and BARBARA THROCKMORTON \\ California State University, Fullerton, California
}

\begin{abstract}
A sentence-demonstration task was used to examine the prose-processing skills of normal and reading-disabled college students. The effects of sentence meaningfulness (meaningful vs. nonsense), sentence length (2 vs. 4 vs. 6 vs. 8 items), and presentation mode (word vs. logographs) were evaluated. The finding of a population membership $\mathbf{x}$ sentence length interaction indicated that performance differences favoring the normal college students emerged when task demands exceeded the operational limits of the disabled student's working memory. In contrast, the effects of sentence meaningfulness and presentation mode did not differ for the two populations. It was suggested that general differences in short-term-memory processing, rather than specific processes associated with decoding of individual printed words, underlie the reading problems of the disabled college students.
\end{abstract}

Researchers have begun to examine the prose-recall skills of learning-disabled adults (see Worden, 1983, Worden, Malmgren, \& Gabourie, 1982, and Worden \& Nakamura, 1982). The theoretical framework that guides this work is the suggestion that limitations in shortterm or working memory may underlie deficits in long-term recall of prose materials. For example, Perfetti and Lesgold (1977) suggested that a reduced speed of processing in short-term memory may cause encoding of prose to lag behind the input. As sentences are read into short-term memory, disabled readers take longer to retrieve verbal codes for individual words. This delay, in turn, impairs their ability to process information about larger units (clauses, sentences) for storage in long-term memory.

A sentence-demonstration task was used in the present study to investigate potential short-term-memory processing differences that distinguish reading-disabled from normal college students. In this task, participants are presented with a sentence to be read aloud, such as "Put the box under the pillow." Props are provided, and participants are subsequently asked to demonstrate the meaning of the sentence from memory. Sentences used in the present study varied in length between two and eight content words. Because of the hypothesized shortterm-memory processing differences between readingdisabled and normal college students, differences between the two groups in sentence-demonstration performance were expected to emerge on long sentences

We wish to thank the staff and clients of the Santa Ana College Learning Center for their kind cooperation. Staff member Penny Gabourie helped with the data collection. A version of this paper was presented at the annual meeting of the American Educational Research Association, New York, March 1982. Authorship is listed alphabetically for the two senior authors, Kee and Worden. Author Kee's mailing address is: Department of Psychology, California State University, Fullerton, CA 92634. (e.g., six- and eight-word sentences), but not on short sentences (e.g., two or four words).

Two kinds of stimuli were selected for use in the present study: printed English words and logographs (whole-word symbols). The logograph stimuli, which were artificially constructed for this study, resembled ideographs employed in Chinese or Japanese. Logographs differ from printed English words in at least three important ways. (1) Logographs should be equally novel to both groups of subjects, whereas printed English words probably are more familiar to normal subjects (Jackson, 1980). (2) Logographs do not permit phonetic decoding, whereas printed English words do (Glushko, 1981). (3) Logographs are visually holistic, whereas printed English words consist of individual letters. Thus, to the extent that words were difficult to process in short-term memory-because they are less frequently experienced in reading by disabled learners, they may require phonetic decoding, and they are constructed from combinations of individual letters-a population $\mathrm{x}$ presentation mode interaction was anticipated in this study. That is, performance differences between the groups were expected to be larger with printed English word orthography than with logographs.

Finally, provisions were made to manipulate the meaningfulness of the sentences presented to participants. The comparison of meaningful prose versus nonsense sentences was included to evaluate the degree to which reading-disabled students differed from normal college students in their ability to use the semantic content of the sentences to facilitate encoding. If learning disabilities are associated with a general short-termmemory deficit, meaningful and nonmeaningful sentences would be expected to be affected similarly. If, on the other hand, the problem is peculiar to memory for meaningful prose, the population difference would be greater for the meaningful sentences. 


\section{METHOD}

\section{Design and Subjects}

The design of the experiment consisted of a $2 \times 2 \times 4 \times 2$ factorial with the between-subjects factor of population (normal vs. reading disabled) and the within-subjects factors of meaningfulness (meaningful vs. nonsense), sentence length (two vs. four vs. six vs. eight items), presentation mode (words vs. logographs), and trials. Fourteen college students from California State University at Fullerton and 14 reading-disabled college students selected from the Santa Ana College Learning Center participated in the study. The reading-disabled subjects all had WAIS scores above 85 and were enrolled in academic, rather than vocational, college studies. Reading-level estimates provided by the Peabody Individual Achievement Test (PIAT) indicated that the normal college students were reading at 12 th-grade or college level, whereas the disabled students were generally reading at the 6 th-grade level.

\section{Material and Procedure}

The subjects were tested individually. At the beginning of each session, the subjects were given $10 \mathrm{~min}$ to study a set of 14 logographs. The logographs represented English word equivalents of nouns (the boy, the girl, the chair, the box, the pillow, and the table), verbs (sit, stand, and put), and prepositions (on, under, beside, and behind). These logographs were drawn on large index cards, and their word equivalents were written on the reverse side. During the $10-\mathrm{min}$ study period, the subjects were told to learn the word equivalents for each logograph. Subsequently, the subjects were tested by a paired-associate anticipation method until they had reached a criterion of two errorless trials. During this phase of the study, the normal college students required fewer trials (mean $=2.29$ ) to reach criterion than did the reading-disabled college students (mean $=4.36)[F(1,26)$ $=16.25, \mathrm{p}<.05]$.

Following logograph learning, the sentence-demonstration task was administered. The subjects were provided with toy props (a pillow, a table, etc.) for acting out the sentences. The sentences were drawn/printed on large index cards and were presented to the subjects manually. The subjects were asked to read aloud the sentence presented on the card and then to demonstrate the meaning of the sentence. Actions and object identifications made by the subjects were recorded for subsequent analysis.

Each subject was presented with eight sentences, one of each sentence length. Sentences were blocked into two trial sets of four sentences each. The four sentences within a trial set represented the factorial combination of two levels of meaningfulness and two levels of presentation mode. Nonsense sentences were generated by scrambling the word order of meaningful sentences. The subjects received systematically different orders of the sentences within blocks.

\section{RESULTS AND DISCUSSION}

The dependent variable selected for analysis was the number of items that the participants successfully referenced in their demonstration of each sentence. Table 1 presents the means for these scores as a function of the experimental conditions. An analysis of variance indicated that the performance of normal students (mean = 4.51) was superior to that of the reading-disabled students (mean $=3.41)[\mathrm{F}(1,26)=13.78]$, meaningful sentences (mean $=4.39$ ) were associated with higher scores than were nonsense sentences (mean $=3.60$ ) $[F(1,26)=86.29]$, and performance increased with sentence length $[\mathrm{F}(3,78)=113.29]$ (all ps $<.001$ ).

Of major interest, however, were the predicted interactions with the factor of population. Consistent with the first prediction that population differences in sentence demonstration would emerge only at the longer sentence lengths, a significant population $\mathrm{x}$ sentence length interaction was detected $[\mathrm{F}(3,26)=12.12$, $\mathrm{p}<.001]$. The mean differences in recall scores, favoring the normal subjects at sentence lengths two, four, six, and eight words, were $+.02,+.30,+1.29$, and +2.51 , respectively. Thus, both reading-disabled and normal college students can successfully process sentences. However, differences emerge when the task demands (e.g., the reading of long sentences) exceed the operational limits of the disabled students' working memory.

The second major issue concerned the extent to which words and logographs would show different encoding effects with reading-disabled and normal college students. None of the critical interactions involving the factors of population and presentation mode were significant ( $\mathrm{ps}>.05$ ). This suggests that differences between printed English word and logograph stimuli, such as novelty, phonetic decoding, and letter segmentation, are not factors that differentially affect short-term-memory processes of reading-disabled and normal students.

A final issue concerned the effects of sentence meaningfulness on the participants' recall performance. No interactions with the factor of population were

Table 1

Mean Number of Sentence Items Demonstrated by Normal and Reading-Disabled College Students as a Function of Meaningfulness, Length, and Presentation Mode

\begin{tabular}{|c|c|c|c|c|c|c|c|c|c|}
\hline \multirow{4}{*}{$\begin{array}{c}\text { Sentence } \\
\text { Meaningfulness }\end{array}$} & \multirow{4}{*}{$\begin{array}{l}\text { Presentation } \\
\text { Mode }\end{array}$} & \multicolumn{8}{|c|}{ Population } \\
\hline & & \multicolumn{4}{|c|}{ Reading Disabled } & \multicolumn{4}{|c|}{ Normal } \\
\hline & & \multicolumn{8}{|c|}{ Sentence Length } \\
\hline & & 2 & 4 & 6 & 8 & 2 & 4 & 6 & 8 \\
\hline Meaningful & $\begin{array}{l}\text { Logographs } \\
\text { Words }\end{array}$ & $\begin{array}{l}1.90 \\
1.97\end{array}$ & $\begin{array}{l}3.64 \\
3.72\end{array}$ & $\begin{array}{l}4.47 \\
4.64\end{array}$ & $\begin{array}{l}5.11 \\
5.39\end{array}$ & $\begin{array}{l}2.00 \\
2.00\end{array}$ & $\begin{array}{l}4.00 \\
4.00\end{array}$ & $\begin{array}{l}5.93 \\
5.93\end{array}$ & $\begin{array}{l}7.82 \\
7.75\end{array}$ \\
\hline Nonsense & $\begin{array}{l}\text { Logographs } \\
\text { Words }\end{array}$ & $\begin{array}{l}1.86 \\
1.75\end{array}$ & $\begin{array}{l}3.11 \\
2.54\end{array}$ & $\begin{array}{l}3.68 \\
4.47\end{array}$ & $\begin{array}{l}3.75 \\
3.71\end{array}$ & $\begin{array}{l}1.93 \\
1.65\end{array}$ & $\begin{array}{l}3.29 \\
2.93\end{array}$ & $\begin{array}{l}5.29 \\
5.25\end{array}$ & $\begin{array}{l}6.60 \\
5.79\end{array}$ \\
\hline Mean & & 1.87 & 3.25 & 4.31 & 4.49 & 1.90 & 3.56 & 5.60 & 6.99 \\
\hline
\end{tabular}


observed ( $\mathrm{ps}>.05$ ), indicating that both groups can take advantage of the semantic content of sentences to facilitate the encoding of those sentences. However, it is interesting to note that a meaningfulness $\mathrm{x}$ sentence length interaction was observed $[\mathrm{F}(3,78)=57.28$, $\mathrm{p}<.001]$, indicating that the superior recall associated with meaningful sentences increased with longer sentences. This interaction was qualified by the three-way interaction of meaningfulness, sentence length, and presentation mode $[F(3,78)=3.18, p<.02]$. Descriptively, this interaction suggests that the advantage associated with meaningful sentences at the longer sentence lengths was larger under printed English word presentation than under logograph presentation. Again, the absence of population interactions in these results shows that these factors affected reading-disabled and normal adults similarly.

In summary, the results of this study extend our knowledge about short-term-memory deficits in learning disabilities in several ways. First, disabled adults performed significantly worse than did normal college students, but only at longer sentence lengths. This finding extends a similar finding by Cohen and Netley (1978) that learning-disabled children performed dramatically worse than normal children on a probe serial recall task involving lists that exceeded their short-termmemory spans. Our finding of a similar effect with adults supports Cohen and Netley's conclusion that the inability of the memory system to cope with an overload is a central feature in learning disabilities. We now know that this problem is not limited to learning-disabled children, but, rather, persists into adulthood.

A second important finding was that performance was equivalent for words versus logographs. This suggests that decoding difficulties reside in the assignment of meaning to visual symbols, regardless of their orthography. In particular, phoneme segmentation is not implicated as a significant factor in the reading disabilities of adults, because logographs are assigned meanings holistically, without recourse to individual letter pronunciation. This result agrees with a very important recent paper by Stevenson, Stigler, Lucker, and Lee (1982), who systematically tested the often cited anecdotal claim that reading disabilities do not exist in Japan and China. Stevenson et al. found strong evidence that reading disabilities $d o$ exist, even where reading is based on ideographic orthography, rather than on grapheme-to-phoneme conversion.

Finally, meaningfulness did not affect the ability groups differently. That is, the differences in performance were of the same magnitude for meaningful versus nonmeaningful prose, thereby ruling out any differential integration of the overall meaning of sentences to aid memory in reading-disabled versus normal college students.

In conclusion, the results support the notion of a short-term-memory bottleneck in learning disabilities, a bottleneck that simply reduces the amount of wordlike information in memory, regardless of orthography and overall effects of meaningfulness. The deficit could be due to a reduced speed of processing (see Perfetti \& Lesgold, 1977) or to a tendency to engage in less rehearsal or elaborative coding (see Torgesen, 1977). Further research will be needed before we can decide which explanation best accounts for the short-termmemory processing deficits. A promising approach will be to evaluate the compensatory effects of memorystrategy instruction with learning-disabled persons (see Worden, 1983).

\section{REFERENCES}

Cohen, R. F., \& Netrey, C. (1978). Cognitive deficits, learning disabilities, and WISC verbal-performance consistency. Developmental Psychology, 14, 624-634.

Guushko, R. (1981). Reading and orthography. In A. M. Lesgold \& C. A. Perfetti (Eds.), Interactive processes in reading. Hillsdale, NJ: Erlbaum.

JACKson, M. D. (1980). Further evidence for a relationship between memory access and reading ability. Journal of Verbal Learning and Verbal Behavior, 19, 683-694.

Perfetti, C. A., \& Lesgold, A. M. (1977). Discourse comprehension and sources of individual differences. In M. Just \& P. Carpenter (Eds.), Cognitive processes in comprehension. Hillsdale, NJ: Erlbaum.

Stevenson, H. W., Stigler, J. W., Lucker, G. W., \& Lee, S. (1982). Reading disabilities: The case of Chinese, Japanese, and English. Child Development, 53, 1164-1181.

Torgesen, J. K. (1977). Memorization processes in readingdisabled children. Journal of Educational Psychology, 79, 571-578.

Worden, P. E. (1983). Memory strategy instruction with the learning disabled. In M. Pressley \& J. Levin (Eds.), Cognitive strategies: Developmental, educational, and treatment-related issues. New York: Springer-Verlag.

Worden, P. E., Malmgren, I., \& Gabourie, P. (1982). Memory for stories in learning disabled adults. Journal of Learning Disabilities, 15, 145-152.

Worden, P. E., \& NAKAmura, G. (1982). Story comprehension and recall in learning disabled vs. normal college students. Journal of Educational Psychology, 74, 633-641.

(Manuscript received for publication January 29, 1984.) 